\title{
Enhancement of coral recruitment by in situ mass culture of coral larvae
}

\author{
A. J. Heyward ${ }^{1, *}$, L. D. Smith ${ }^{1}$, M. $\operatorname{Rees}^{1}$, S. N. Field ${ }^{2}$ \\ ${ }^{1}$ Australian Institute of Marine Science, PO Box 83, Fremantle, Western Australia 6959, Australia \\ ${ }^{2}$ Department of Marine Sciences and Coastal Management, University of Newcastle upon Tyne, Newcastle NE1 7RU, \\ United Kingdom
}

\begin{abstract}
New technologies for culturing and settling scleractinian coral larvae in the field are required to elucidate the role of recruitment in population dynamics and to provide options for reef rehabilitation. Natural multi-species aggregations of coral embryos, which frequently form slicks on the sea surface after large-scale annual spawnings, were identified as a potential resource for mass coral culture. Slicks containing billions of embryos were found at sea and several million embryos were sub-sampled and successfully cultured in simple floating ponds, moored over the reef. Coral larvae were maintained in the floating ponds until competent to settle, and then seeded onto the reef environment via hoses from the ponds to mesh enclosures temporarily fixed to the reef substratum. Reefal areas exposed to the cultured larvae exhibited a dramatic enhancement of coral larval recruitment compared to natural rates. The results demonstrate the ability to seed defined areas of reef with controlled densities of recruits. We conclude that natural spawning slicks, which have been noted on numerous reefs throughout the world, provide opportunities for very large-scale culture of corals, which may have application in reef rehabilitation and management strategies where natural recruitment is limited.
\end{abstract}

KEY WORDS: Coral $\cdot$ Recruitment $\cdot$ In situ $\cdot$ Mass culture $\cdot$ Larvae

Resale or republication not permitted without written consent of the publisher

\section{INTRODUCTION}

Recruitment plays a critical role in the persistence and resilience of reef coral populations (Richmond 1997) but its relative importance in coral population and community dynamics can vary according to species, habitat and reef location (e.g. Connell et al. 1997). Recent data indicate quite different patterns of recruitment and post-recruitment mortality occurring in reef crest coral communities along the length of the Great Barrier Reef (Hughes et al. 1999). Characterising the site-specific nature of processes and mechanisms influencing the arrival and survival of corals onto reefs is necessary for sound reef management. For scleractinian corals, however, it is difficult to assess the relative importance of recruitment and post-recruitment processes in sustaining coral populations, unless experi-

*E-mail: a.heyward@aims.gov.au mental manipulation of recruitment in situ can be accomplished (Caley et al. 1996). Knowledge of coral reproduction, in particular broadcast spawning periods, has now reached a point where access to significant numbers of coral gametes is possible at many locations and such studies could be attempted.

Since the early mid-1980s, broadcast spawning rather the brooding has been noted as the most common mode of sexual reproduction in the Scleractinia (Harrison et al. 1984, Babcock et al. 1986). Within a few years of the discovery of the mass coral spawning phenomenon in Australia, similar spawning was reported from several countries (see reviews by Harrison \& Wallace 1990, Richmond \& Hunter 1990). Coral spawning periods have subsequently been directly recorded or inferred at many additional sites including Japan (Hayashibara et al. 1993, Van Woesik 1995), the western Atlantic (Hagman et al. 1998), the Caribbean (de Graaf et al. 1999), the mid-Indian Ocean (Siers \& 
Olive 1994) and the Middle East (Fadlallah 1996, Shlesinger et al. 1998). Broadcast spawnings are generally reported to be annual phenomena and are reasonably predictable for a given location. The consequent ability to anticipate the major coral spawning periods and gather coral gametes has facilitated a new range of studies including investigations of coral fertilisation, embryogenesis and settlement (see Heyward \& Babcock 1985, Babcock \& Heyward 1986, Harrison \& Wallace 1990, Morse et al. 1996), including attempts to seed lab-cultured larvae and recruits into the field (Babcock \& Mundy 1988, Richmond et al. 1999). These types of studies have relied on the collection of live coral from the reef, and subsequent spawning and harvesting of gametes in laboratory tanks. While this approach has facilitated basic research, it requires the collection of corals, it is restrictive in terms of the volume of gametes and the number of species that can be used and typically requires the support of marine laboratory infrastructure.

To advance studies into coral recruitment and postrecruitment processes, larger-scale larval culture is required. Ideally the restrictions inherent in previously reported laboratory-based approaches need to be overcome. Developing methodology to mass culture millions of coral larvae also promises the potential to augment existing approaches to reef remediation. This paper provides the first data on a simple but effective method to mass culture both wild-caught and laboratory-spawned coral larvae in floating ponds moored over the reef and to control their release onto the reef as competent larvae.

\section{MATERIALS AND METHODS}

Larval culture. A set of custom-designed floating culture ponds were developed (Fig. 1) specifically to enhance the survival of coral larvae from broadcast spawning species. The larval rearing ponds are self-contained, floating pools (see Fig. 1) moored in position over the reef with an anchor and rope. The pool component is approximately $1.8 \mathrm{~m}$ diameter and is made of a foodgrade, nylon-reinforced vinyl fabric. Each pool is positioned within a PVC raft frame that measures $2 \times 2 \mathrm{~m}$. The frame is held above the surrounding water by car tyre inner tubes that are positioned under each corner of the PVC frame. Fresh seawater from outside the pond was provided throughout the experiment by a timer-controlled bilge pump $\left(1100 \mathrm{l} \mathrm{h}^{-1}\right)$ switched on for $30 \mathrm{~s}$ every $3 \mathrm{~min}$, yielding approximately $600 \mathrm{l} \mathrm{h}^{-1}$ of water exchange. Two nylon mesh $(125 \mu \mathrm{m})$ windows $(450 \times$ $150 \mathrm{~mm}$ ) on either side of the pool allowed for the flow-through seawater exchange, while retaining the coral larvae. Mesh windows and the sides of the pool were regularly cleaned by hand with gentle brushing.

In March 1997, the majority of the acroporids in Coral Bay spawned 7 nights after the full moon, between 21:15 and 22:30 $\mathrm{h}$, causing a large slick containing billions of gametes and embryos to form within the bay. A small fraction of the slick was used to culture millions of potential coral recruits. Samples were collected from the slick on the ocean surface by

Fig. 1. Schematic of floating larval culture pond and reseeding system 
hand using $10 \mathrm{l}$ buckets. The gametes were transported to 4 larval culture ponds, which were moored a few hundred metres from shore. It was calculated that approximately 4 million coral embryos from 18 species of acroporids were deposited into the 4 culture ponds (approximately 1 million per pond) on the night of spawning. The following $7 \mathrm{~d}$ involved minimal husbandry to maintain the culture with regular cleaning of the screen mesh as well as pool membranes, and battery changes for the pumps as required.

To determine the number of larvae with each larval rearing pond, 10 replicate samples $(25 \mathrm{ml}$ each) were taken from each pool. Each pool was rigorously stirred to remove any stratification of the developing coral larvae. The replicate samples were taken from a range of depths. Using a dissecting microscope, the total number of larvae was counted in each sample. Subsequently the density of coral larvae was measured in this way approximately every $12 \mathrm{~h}$. Survivorship in each of the pools was followed until the time of reseeding. On Day 7, coral larvae from 2 additional ponds was added to each of the 4 experimental ponds until coral larva density was between 400 and $800 \mathrm{l}^{-1}$.

Larval reseeding. Larval competency through time was monitored by sub-sampling from the floating pond cultures and exposing the larvae to crustose coralline algae in vitro as described by Heyward \& Negri (1999). Six days after embryos were collected, $80 \%$ were competent to settle and it was decided to initiate the seeding experiment. Each of the larval rearing ponds was towed behind a small boat to 1 of 4 reef areas within Coral Bay and used for replicated seeding trials. The pools and their floating support frames were frequently agitated by small surface waves and wind gusts, causing continuous movement of water within the ponds and subsequent good mixing of the larval cohorts. Once in position at a seeding station the mesh windows in the walls of the culture pond were covered and the bilge pumps turned on constantly. This caused the water level to rise inside the pond, creating a pressure head, which was used to flush the larvae down a plastic swimming pool hose that had been inserted into the base of the pool. The hose was connected into the roof of a floorless, mesh tent $(1.8 \times 1 \mathrm{~m}$, nominal $200 \mu \mathrm{m}$ mesh, Fig. 1) which was placed on reef substratum and retained the larvae as they were pumped out of the hose (Fig. 1). The area of reef substrate under the mesh tent defined the experimental quadrat for each reseeding treatment. Location of the treatment and control sites drew on extensive surveys of the benthic and reef fish communities throughout Coral Bay (e.g. Halford 1996). All sites were selected within the same broad habitat zone within the sheltered Coral Bay lagoon and consisted of low-relief areas of limestone substrate and rubble amidst small patches of live coral.
There were 2 seeding treatments. In Treatment 1 each pond was pumped for 20 min into the mesh enclosed quadrat. In Treatment 2 the larval rearing pond was moved to an adjacent area and the rest of the larvae were pumped into a separate mesh-enclosed quadrat over a $12 \mathrm{~h}$ period. Calculations of larval density in the ponds suggest that 15 to $20 \%$ of the larvae were pumped into the Treatment 1 areas, while the remainder were pumped into the quadrats used for Treatment 2.

Recruitment density was monitored within treatment quadrats, in control areas adjacent to but outside the mesh enclosures and at control areas randomly distributed throughout Coral Bay using terracotta tiles. These tiles had been placed in the water $3 \mathrm{wk}$ prior to the seeding to allow a biofilm to establish on the tiles. The same approach had been used to census natural levels of recruitment at the same time of year at Coral Bay, between 1996 and 1999, which revealed very low levels of recruits $\left(0.3\right.$ recruits $\left.\mathrm{h}^{-1}\right)$. Consequently the preconditioned tiles were not censused prior to being used in the treatments. Control tile results from this study confirmed the same level of background recruitment once again. Within each of the treatment quadrats, 6 conditioned terracotta tiles $(110 \times 110 \times 10 \mathrm{~mm})$ were attached to the substratum. The tiles were attached to the reef substratum using a roofing nail $(10 \mathrm{~cm}$ long $)$ and a PVC pipe spacer (4 cm diameter, $2 \mathrm{~cm}$ length). Six weeks after seeding, all tiles were removed and censused under a stereo microscope. Each coral recruit (both dead and alive) was identified to 1 of 4 groups (Family Acroporidae, Family Pocilloporidae, Family Poritidae or Other) and the position that they settled on the tile (upper, lower or horizontal) was recorded.

\section{RESULTS}

\section{Larval composition, survivorship and competency}

On the night the embryos were collected, only scleractinian corals from the Family Acroporidae were observed spawning by divers in Coral Bay. The species included Acropora formosa, A. grandis, A. hyacinthus, A. humulis, A. millepora, A. nobilis, A. secale, and A. tenius. In the floating ponds the larval survivorship rate was constant through time (Type II survivorship sensu Begon et al. 1986, p. 140), with a pond mean of $2 \times 10^{5}$, or $5 \%$, of the original stock surviving to $6 \mathrm{~d}$ (Fig. 2). While larval survival was not significantly different between 3 of the larval rearing ponds, 1 pond had significantly lower survival. The low larval survival in this pond was due to the partial sinking of the pond on Day 5, in which many larvae escaped (Fig. 2). Laboratory experiments revealed $80 \%$ or $1.6 \times 10^{5}$ of these surviving larvae were competent to settle when 


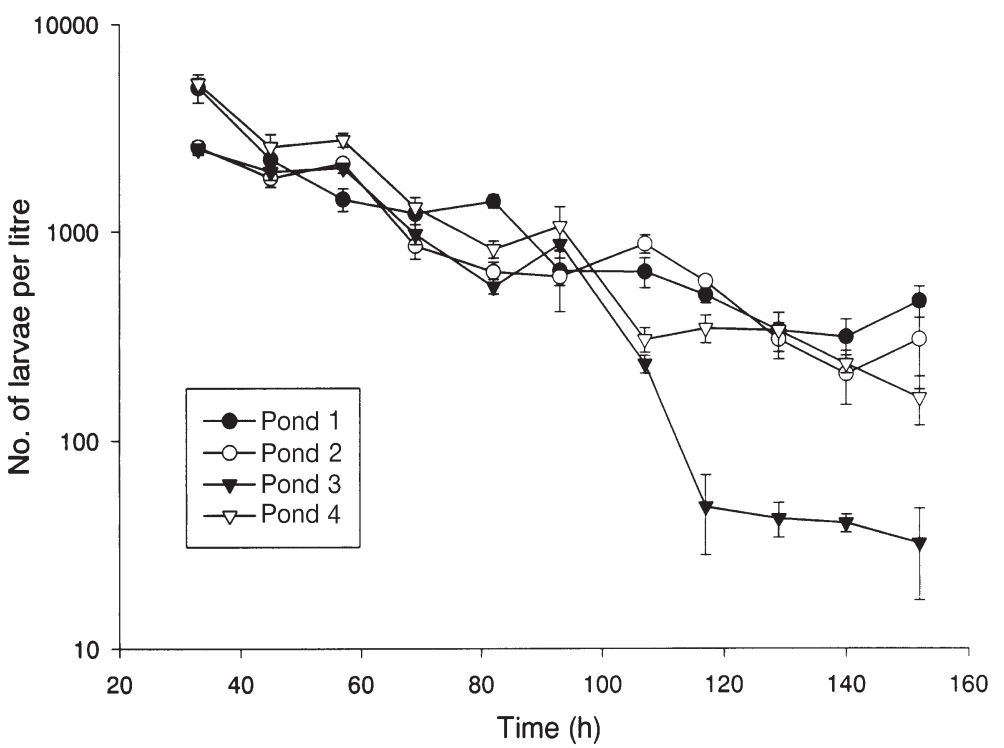

Fig. 2. Mean density $( \pm \mathrm{SE})$ of live coral larvae over time in the larval rearing ponds. The volume of each pond was approximately $1500 \mathrm{l}$

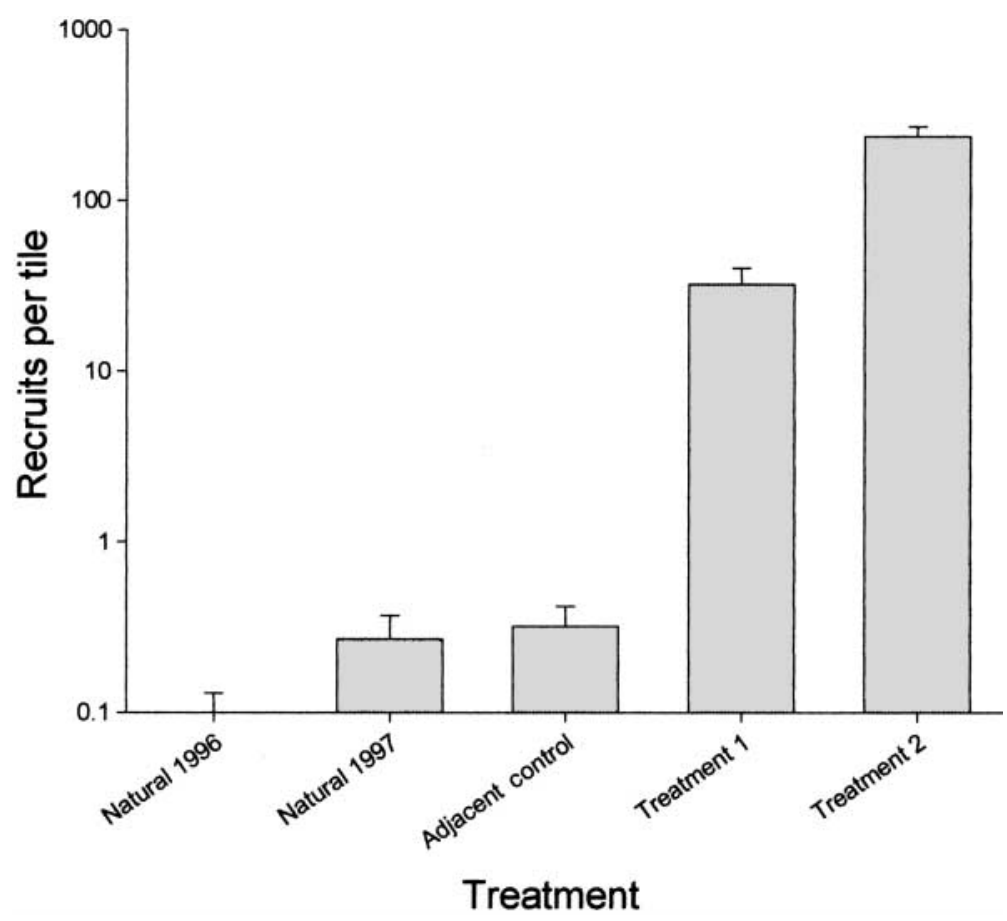

Fig. 3. Comparison of mean recruit abundance per tile, per treatment $( \pm$ SE) for seeded and control areas. Natural 1996 and Natural 1997: background recruitment in the inner reef areas of Coral Bay in 1996 and 1997, based on 400 tiles deployed and recovered from 8 sites; Adjacent control: recruitment on tiles deployed and recovered adjacent to the seeding mesh dome enclosures; Treatment 1: recruitment within the seeding quadrats that received the initial flow of larvae from the floating ponds for $20 \mathrm{~min}$; Treatment 2: recruitment within the seeding quadrats that received the major flow of larvae from the floating ponds for $12 \mathrm{~h}$ presented with a crustose coralline alga settlement cue at Day 6 (see Heyward \& Negri 1999).

\section{Recruitment}

Background levels of coral recruitment in the inner part of Coral Bay were known to be low in 1994 and 1996 (Harriott \& Simpson 1997, this study) and remained low during 1997 (Fig. 3). Recruitment was greatly enhanced in the experimental quadrats seeded with mass cultured coral larvae. A total of 6539 coral recruits were counted on the tiles 4 wk after their seeding. Coral larvae settled on the upper, lower and horizontal surfaces of the experimental tiles. However the majority settled on the lower horizontal surfaces of the tiles $(60 \%)$ compared to the vertical surfaces (33\%) and upper surfaces (7\%). The proportion of recruits on each surface did not change as settlement density increased. Only 18 recruits were from brooding species and these were all members of the Family Pocilloporidae. Consequently, the vast majority of recruits were broadcast-spawning corals and all of these were acroporids (Family Acroporidae).

Overall coral recruitment varied greatly between treatments (Fig. 3). Recruitment in the most highly seeded areas (Treatment 2; 236 recruits per tile) was 100 -fold more than the natural levels of recruitment in Coral Bay (0.27 recruits per tile). Furthermore, there were major differences between the 2 seeding treatments, with the long duration treatment (Treatment 2) having 10 times more recruitment than the shorter duration treatment (Treatment 1; 23 recruits per tile). Recruitment density varied greatly within treatments (Fig. 4). For example, the recruitment rates within the high treatment varied 5-fold, with rates between 80 and 384 recruits per tile. The shorter duration, seeded treatment was even more variable, varying between 0.17 and 68 recruits per tile.

\section{DISCUSSION}

We have demonstrated that wild-caught coral larvae, often present in great numbers on reefs after the predictable annual spawning events, provide a viable resource for mass culture of juvenile corals in simple sea-culture systems. Furthermore, these mass reared larvae can be deployed in a controlled way to artificially enhance coral recruitment in situ. The demonstration that 


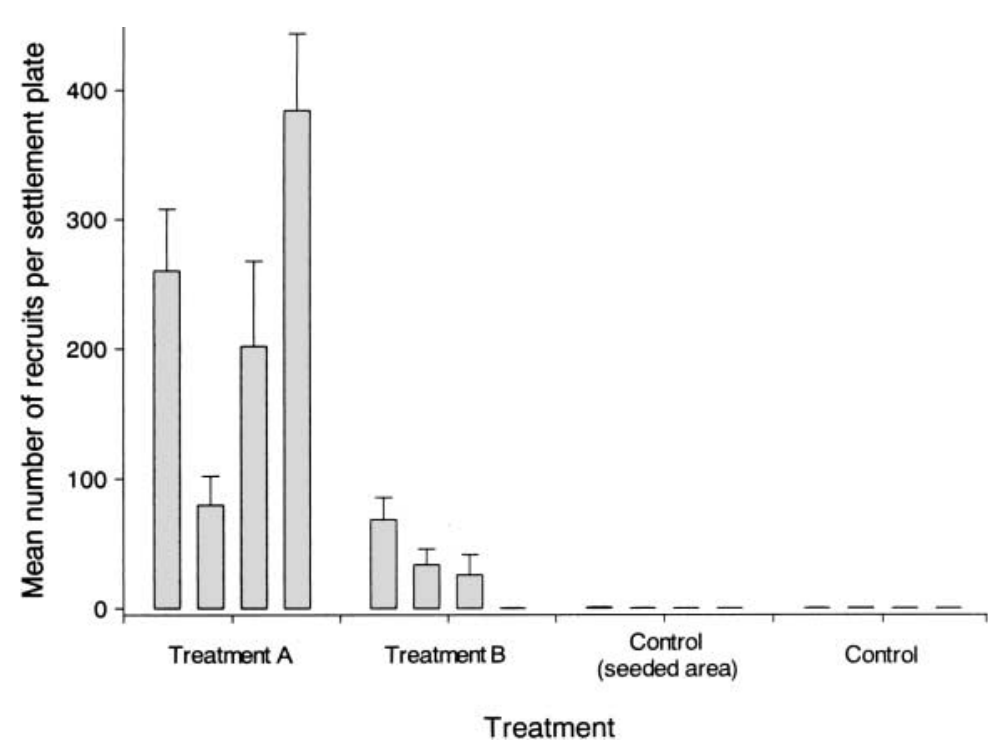

Fig. 4. Variability in the recruitment rates within and between treatments. Mean number of recruits $( \pm \mathrm{SE})$ per settlement tile for each of the 4 replicates performed for each of the seeding and control treatments

recruitment density could be manipulated by varying the larval supply into the experimental quadrat is notable. This approach should permit experiments to manipulate coral recruitment density while controlling other factors (e.g. predators, competition, etc.). For example, a series of recruitment densities could be applied to differing areas of a reef that are likely to have similar mortality agents (exposure, grazing intensity, depth, etc.) and an assessment made of the effect on subsequent population sizes. Experimental recruitment densities could be manipulated anywhere from background to the highest recorded in natural recruitment studies. Recruit densities in the Coral Bay treatments seeded for $12 \mathrm{~h}$ were almost double maximum natural settlement levels recorded from a 5 yr Great Barrier Reef study (see Sammarco 1994). Mean settlement rates in Treatment 1 (using the initial 20 min seeding time) were significantly lower than rates in Treatment 2 but were still 2 orders of magnitude greater than natural background levels of recruitment in the inner reef of Coral Bay (Fig. 3). We believe that this technique provides the means to test, directly on the reef, a variety of hypotheses related to the importance of recruitment in determining subsequent coral population numbers (see Caley et al. 1996).

The ability to deliver a controlled level of coral recruitment to reefs and monitor survival will provide opportunities for intensive study of reef resilience and for assessing impacts of varying reef management strategies. Hypotheses regarding the role of recruitment limitation in reef recovery, or the influence of chronic pollution or substrate degradation on post- recruitment survival could be tested by reseeding known quantities of recruits to affected locations. Furthermore, the rearing of coral larvae could provide a new, non-destructive technology in rehabilitating small areas of damaged coral reef communities. In this study, we have shown that mass rearing of coral larvae is feasible without laboratory or field station infrastructure and can be used to dramatically enhance natural coral recruitment directly onto reef habitat, albeit at small spatial scales. While the level of larval production described is adequate for experimental manipulations, very large scale larval harvesting and culture should be possible given knowledge of spawning times and, in particular, conditions favourable to slick formation. Naturally occurring spawn slicks or larval aggregations provide a highly diverse and abundant array of viable coral larvae and may occur in many reefs areas, e.g. Taiwan (Kawaguti 1940), Bermuda (Butler 1980), American Samoa (Itano \& Buckley 1988), the Great Barrier Reef (Oliver \& Willis 1987), and Western Australia (Simpson et al. 1993). Access to slicks would provide billions of larvae for culture, but the increasing predicability of coral spawning times worldwide may permit direct field harvesting of gametes from spawning colonies (e.g. Coll et al. 1995) or from the plankton (e.g. Hodgson 1985). The survival in the larval rearing ponds exhibited a Type II survivorship curve (Fig. 2). There is considerable scope for research, studying both culture systems and conditions associated with open water spawn slicks, to elaborate the causes of larval mortality in the plankton. Noting advances in aquaculture of many marine invertebrates (e.g. Douillet 1989), refinement of these culture systems to enhance the yield of competent coral larvae by manipulating physical and microbial aspects of water quality should be possible.

Acknowledgements. We thank J. Gilmour, K. Brooks and the numerous volunteers for their assistance in the field. Research undertaken at Ningaloo was covered by permit SF002708 from the Department of Conservation and Land Management. This is contribution number 1102 of the Australian Institute of Marine Science.

\section{LITERATURE CITED}

Babcock RC, Heyward AJ (1986) Larval development of certain gamete-spawning scleractinian corals. Coral Reefs 5: 111-116

Babcock R, Mundy C (1996) Coral recruitment: consequences of settlement choice for early growth and survivorship in two scleractinians. J Exp Mar Biol Ecol 206:179-201

Babcock RC, Bull GD, Harrison PL, Heyward AJ Oliver, JK, Wallace CC, Willis BL (1986) Synchronous spawnings of 
105 scleractinian coral species on the Great Barrier Reef. Mar Biol 90:379-394

Begon M, Harper JL, Townsend CR (1986) Ecology: individuals, populations and communities. Blackwell Scientific Publications, Oxford

Butler JN (1980) Pink stripe on the ocean. Nat Hist 89(7):62-63

Caley MJ, Carr MH, Hixon MA, Hughes TP, Jones GP, Menge BA (1996) Recruitment and the local dynamics of open marine populations. Annu Rev Ecol Syst 39:477-500

Coll JC, Leone PA, Bowden BF, Carroll AR and 5 others (1995) Chemical aspects of mass spawning in corals II. (-)-Epithunbergol, the sperm attractant in the eggs of the soft coral Lobophytum crassum (Cnidaria: Octocorallia). Mar Biol 123(1):137-143

Connell JH, Hughes TP, Wallace CC (1997) A 30-year study of coral abundance, recruitment, and disturbance at several scales in space and time. Ecol Monogr 67(4):461-488

de Graaf M, Geertjes GJ, Videler JJ (1999) Observations on spawning of scleractinian corals and other invertebrates on the reefs of Bonaire (Netherlands Antilles, Caribbean). Bull Mar Sci 64(1):189-194

Douillet P (1989) Effect of bacteria on the culture of larvae of the Pacific oyster Crassostrea gigas. (Thunberg). J Shellfish Res 8(2):412

Fadlallah YH (1996) Synchronous spawning of Acropora clathrata coral colonies from the western Arabian Gulf (Saudi Arabia). Bull Mar Sci 59:209-216

Hagman DK, Gittings SR, Deslarzes KJP (1998) Timing, species participation, and environmental factors influencing annual mass spawning at the Flower Garden Banks (Northwest Gulf of Mexico). Gulf Mex Sci 16(2):170-179

Halford A (1996) Recovery of a fish community six years after a catastrophic mortality event. Proc 8th Int Coral Reef Symp, Panama, 1:1011-1016

Harriott VJ, Simpson J (1997) Coral recruitment on tropical and subtropical reefs in Western Australia. Proc 8th Int Coral Reef Symp, Panama, 2:1191-1196

Harrison PL, Wallace CC (1990) Reproduction, dispersal and recruitment of scleractinian corals. In: Dubinsky Z (ed) Ecosystems of the world 25: coral reefs. Elsevier, Oxford, p 133-208

Harrison PL, Babcock RC, Bull GD, Oliver JK, Wallace CC, Willis BL (1984) Mass spawning in tropical reef corals. Science 222:1186-1189

Hayashibara T, Shimoike K, Kimura T, Hosaka S, Heyward A, Harrison P, Kudo K, Omori M (1993) Patterns of coral spawning at Akajima Island, Okinawa, Japan. Mar Ecol Prog Ser 101:253-262

Heyward AJ, Babcock RC (1985) Embryonic and postembryonic development of some hermatypic corals. Proc 5th Int Coral Reef Congress, Tahiti, 2:176

Editorial responsibility: Charles Birkeland (Contributing Editor), Honolulu, Hawaii, USA
Heyward AJ, Negri AP (1999) Natural inducers for coral larval metamorphosis. Coral Reefs 18:273-279

Hodgson G (1985) Abundance and distribution of planktonic coral larvae in Kaneohe Bay, Oahu, Hawaii. Mar Ecol Prog Ser 26:61-71

Hughes TP, Baird AH, Dinsdale EA, Moltschaniwskyj NA, Pratchett MS, Tanner JE, Willis BL (1999) Patterns of recruitment and abundance of corals along the Great Barrier Reef. Nature 397:59-63

Itano D, Buckley T (1988) Observations of the mass spawning of corals and palolo (Eunice viridis) in American Samoa. Report to the American Department of Marine and Wildlife Resources, American Samoa, November 1988

Kawaguti S (1940) An abundance of reef coral planulae in the plankton. Zool Mag 52:31

Morse ANC, Iwao K, Baba M, Shimoike K, Hayashibara T, Omori M (1996) An ancient chemosensory mechanism brings new life to coral reefs. Biol Bull 191:149-154

Oliver JK, Willis BL (1987) Coral-spawn slicks in the Great Barrier Reef: preliminary observations. Mar Biol 94: 521-529

Richmond RH (1997) Reproduction and recruitment in corals: critical links in the persistence of reefs. In: Life and death of coral reefs. Chapman \& Hall, New York, p 175-197

Richmond RH, Hunter CL (1990) Reproduction and recruitment of corals: comparisons among the Caribbean, the tropical Pacific, and the Red Sea. Mar Ecol Prog Ser 60: 185-203

Richmond RH, Romano S, Leota S (1999) Coral cultivation and its application to reef restoration, environmental assessment, monitoring and the aquarium trade. Abstracts from the International Conference on Scientific Aspects of Coral Reef Assessment, Monitoring and Restoration. 14-16 April 1999 Ft. Lauderdale, National Coral Reef Institute (NCRI), Nova Southeastern University, FL

Sammarco PW (1994) The bio-physics of marine larval dispersal. In: Sammarco PW, Heron M (eds) Coastal and estuarine studies, Vol 45, American Geophysical Union, Washington, DC, p 35-105

Shlesinger Y, Goulet TL, Loya Y (1998) Reproductive patterns of scleractinian corals in the northern Red Sea. Mar Biol 132:691-701

Siers CS, Olive PW (1994) Reproduction and reproductive variability in the coral Pocillopora verrucosa from the Republic of Maldives. Mar Biol 118:713-722

Simpson CJ, Cary JL, Masini RJ (1993) Destruction of corals and other reef animals by coral spawn slicks on Ningaloo Reef, Western Australia. Coral Reefs 12:185-191

Van Woesik R (1995) Coral communities at high latitude are not pseudo-populations: evidence of spawning at 32 degree N, Japan. Coral Reefs 14:119-120

Submitted: August 17, 2000; Accepted: July 2, 2001

Proofs received from author(s): March 8, 2002 